Check for updates

1 BMJ Medicine, London, UK

2 The BMJ, London, UK

3 BMJ Journals, London, UK

Correspondence to: S Cook scook@bmj.com

Cite this as: $B M J 2021 ; 374: n 1883$

http://dx.doi.org/10.1136/bmj.n1883

Published: 28 July 2021

\title{
Introducing BMJ Medicine
}

\author{
A new multispecialty journal from The BMJ \\ Sophie Cook, ${ }^{1}$ Emma Doble, ${ }^{2}$ Kamran Abbasi, ${ }^{2}$ Claire Rawlinson, ${ }^{3}$ Fiona Godlee ${ }^{2}$
}

The covid-19 pandemic has been accompanied by an explosion in scientific discourse across mainstream media, social media, preprint servers, ${ }^{1}$ and peer reviewed journals. Alongside the remarkable medical advances, we have witnessed a barrage of misinformation and bad science that has threatened public health and patient care. The hunger for timely and reliable medical information during the pandemic has reinforced the importance of robust journal processes in advancing knowledge and managing messages to maximise benefit and minimise harm. But despite rapid growth in the number of journals, the proportion that are professionally edited remains small.

With these things in mind, The BMJ will launch a new open access multispecialty journal, BMJ Medicine, ${ }^{2}$ in the last quarter of 2021.

Closely aligned with The BMJ, BMJ Medicine will provide an important space for high quality multidisciplinary discussion and debate for a broad international readership and will adopt the values, editorial standards, and author service for which The $B M J$ is renowned. It will offer a trusted open access home for multispecialty research, including research based on new and emergent methods. The journal will also publish articles on topical issues in statistics and research methods and reporting, as well as in-depth specialist reviews that focus on mechanisms of disease and the latest diagnostic and therapeutic advances.

While many established journals are re-engineering their policies, processes, and people to embrace new ways of publishing, BMJ Medicine will embed these from the start and will build on the campaigning innovative policies of The BMJ.

\section{Transparent, open, honest, and quick}

BMJ Medicine is committed to promoting transparency throughout the publication process. We operate open peer review, including publication of the full prepublication history (editor and reviewer reports and previous versions of manuscripts) for each research paper. We will also encourage post-publication correspondence to advance the scientific debate.

As an open access journal, BMJ Medicine will be compliant with Plan S and other funders' open access mandates for the publication of research. BMJ operates a generous waiver policy through which we aim to ensure equity and opportunity for unfunded as well as funded research. ${ }^{3}$ The journal will adopt best practices in reporting ${ }^{4}$ and abide by The BMJ's data sharing policy. ${ }^{56}$ As authors, you will be encouraged to link to the raw data from your research.
Speed of publication is important for the

dissemination of good science. Our in-house editors will process acceptances quickly and be available to support you throughout your paper's journey. For research that falls outside BMJ Medicine's remit, we will help you find the best possible home for your work within the wider BMJ family of journals. ${ }^{7}$ Our dedicated author transfer team will guide you through this process, sharing peer review reports across our journals to expedite decisions and reduce duplication of effort.

\section{Spreading the word}

We will ensure your work is widely disseminated to maximise its impact. We will work with you to optimise the presentation of your research-for example, through visual abstracts, ${ }^{8}$ podcasts, commissioned editorials, and patient commentaries. Our experienced media team will work with you on press releases, and we will share findings with BMJ's large international readership through our websites and social media channels. You will also be invited to write accompanying opinion ${ }^{9}$ articles on bmj.com to tell the story behind your research.

\section{Everyone included}

BMJ Medicine will be a truly inclusive and global journal, with an international editorial board that reflects the diversity in medicine and society. Our belief is that diversity among our editorial board, authors, and reviewers will enrich and broaden our content, making it ever more relevant to researchers and clinicians around the world. As a new journal, BMJ Medicine can embed and monitor this diversity from the outset.

BMJ Medicine is committed to partnering with patients and the public. We believe this is the only way to ensure that medical journals are relevant, practical, and clinically impactful. We will promote co-production of research and educational content, and articles will be reviewed by patients alongside traditional peer review. We will also work closely with The BMJ's patient editor team and the wider patient community to continually develop our policies, processes, and content.

Research contributions are welcome from all medical specialties. In a world in which people are living longer and with more complex comorbidities, and where social determinants are leading to greater health inequities globally, we must create opportunities for interdisciplinary and transdisciplinary conversations to ensure we do not lose connections within and across specialties. We also welcome research on the greatest threats of our time, which transcend all specialties: most notably pandemics and the climate emergency. We want to 
provide doctors, researchers, policy makers, patients, and the public with the information and support they need to make healthcare sustainable and to protect future generations.

In envisaging BMJ Medicine, we allowed ourselves to imagine what the most ethical journalbuilt on the most principled editorial and publishing policies would look like. We believe BMJ Medicine is that journal. We hope you will consider it as a home for your work ${ }^{10}$ and as a trusted forum for sharing information and ideas. Please join us as we work to secure the health of people and the planet.

For more information or to discuss a submission please contact scook@bmj.com.

Competing interests: We have read and understood BMJ policy on declaration of interests and have no relevant interests to declare.

Provenance and peer review: Commissioned; not externally peer reviewed.

1 Sever R, Inglis J, Bloom T, Rawlinson C. Pandemic preprints: a duty of responsible stewardship. BMJ Opinion, 27 Apr 2021. https://blogs.bmj.com/bmj/2021/04/27/pandemic-preprints-a-dutyof-responsible-stewardship/

2 BMJ Medicine. bmjmedicine.bmj.com

3 BMJ author hub. Waivers and discounts. https://authors.bmj.com/open-access/fees-discounts/

4 Equator Network. https://www.equator-network.org/

5 Loder E, Groves T. The BM/ requires data sharing on request for all trials. BMJ2015;350:h2373. doi: 10.1136/bmj.h2373 pmid: 25953153

6 Taichman DB, Sahni P, Pinborg A, etal. Data sharing statements for clinical trials. BMJ 2017;357:j2372. doi: 10.1136/bmj.j2372 pmid: 28584025

7 BMJ Journals. https://journals.bmj.com/

8 BMJ visual abstracts. https://www.bmj.com/content/bmj-visual-abstracts

9 Dobson J, Abbasi K. Welcome to BMJ Opinion. BMJ 2017;356:j631. doi: 10.1136/bmj.j631 pmid: 28174152

10 ScholarOne Manuscripts. Submissions for BMJ Medicine. https://mc.manuscriptcentral.com/bmimedicine 